\title{
Correction to: A robust rotation resilient video watermarking scheme based on the SIFT
}

\section{Kh. Manglem Singh ${ }^{1}$}

Published online: 8 November 2017

(C) Springer Science+Business Media, LLC 2017

\section{Correction to: Multimed Tools Appl}

https://doi.org/10.1007/s11042-017-5213-9

Equations 9 and 10 in the original publication of this article contained an error. The correct equations are presented in this correction article.

$$
\begin{aligned}
& \text { For } W\left(k_{1}, k_{2}\right)=0, \\
& \left\{\begin{array}{l}
H H^{\prime}(m, n)=\frac{H H(m, n)+H H(p, q)}{2}-\frac{T}{2} \\
H H^{\prime}(p, q)=\frac{H H(m, n)+H H(p, q)}{2}+\frac{T}{2}
\end{array}\right. \\
& \left\{\begin{array}{l}
H o r \\
H H^{\prime}(m, n)=\frac{H H(m, n)+H H(p, q)}{2}+\frac{T}{2} \\
H H^{\prime}(p, q)=\frac{H H(m, n)+H H(p, q)}{2}-\frac{T}{2}
\end{array}\right.
\end{aligned}
$$

The online version of the original article can be found at https://doi.org/10.1007/s11042-017-5213-9.

Kh. Manglem Singh manglem@gmail.com

1 Department of Computer Science \& Engineering, National Institute of Technology Manipur, Imphal, India 